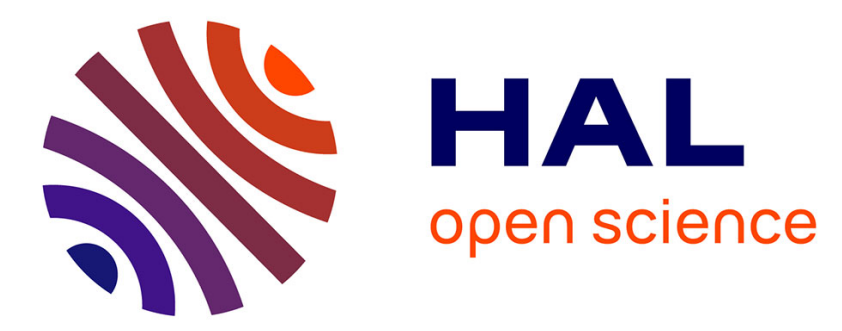

\title{
Microstructural analysis of wear micromechanisms of WC-6Co cutting tools during high speed dry machining
}

Tchadja Kagnaya, Christine Boher, Laurence Lambert, Myriam Lazard, Thierry Cutard

\section{- To cite this version:}

Tchadja Kagnaya, Christine Boher, Laurence Lambert, Myriam Lazard, Thierry Cutard. Microstructural analysis of wear micromechanisms of WC-6Co cutting tools during high speed dry machining. International Journal of Refractory Metals and Hard Materials, 2014, 42, p.151-162. 10.1016/j.ijrmhm.2013.08.017 . hal-00995670

\section{HAL Id: hal-00995670 https://hal.science/hal-00995670}

Submitted on 19 Sep 2018

HAL is a multi-disciplinary open access archive for the deposit and dissemination of scientific research documents, whether they are published or not. The documents may come from teaching and research institutions in France or abroad, or from public or private research centers.
L'archive ouverte pluridisciplinaire HAL, est destinée au dépôt et à la diffusion de documents scientifiques de niveau recherche, publiés ou non, émanant des établissements d'enseignement et de recherche français ou étrangers, des laboratoires publics ou privés. 


\title{
Microstructural analysis of wear micromechanisms of WC-6Co cutting tools during high speed dry machining
}

\author{
T. Kagnaya ${ }^{\mathrm{a}, \mathrm{b}, *}$, C. Boher ${ }^{\mathrm{a}}$, L. Lambert ${ }^{\mathrm{a}, 1}$, M. Lazard $^{\mathrm{b}, 2}$, T. $^{\text {Cutard }}{ }^{\mathrm{a}}$ \\ a Université de Toulouse, Mines Albi, INSA, UPS, ISAE, ICA (Institut Clément Ader) Campus Jarlard, F 81013 Albi Cedex 09, France \\ ${ }^{\mathrm{b}}$ Université de Lorraine, Laboratoire d'Énergétique et de Mécanique Théorique et Appliquée, LEMTA CNRS-UMR 7563, Ecole Nationale Supérieure des Mines de Nancy (ENSMN), \\ GIP-InSIC, 27 rue d'Hellieule, 88100 Saint-Dié-des-Vosges, France
}

\begin{abstract}
A B S T R A C T
This original study investigates the damages of WC-6Co uncoated carbide tools during dry turning of AISI 1045 steel at mean and high speeds. The different wear micromechanisms are explained on the basis of different microstructural observations and analyses made by different techniques: (i) optical microscopy (OM) at macro-scale, (ii) scanning electron microscopy (SEM), with back-scattered electron imaging (BSE) at micro-scale, (iii) energy dispersive spectroscopy (EDS), $\mathrm{X}$ ray mapping with wavelength dispersive spectroscopy (WDS) for the chemical analyses and (iv) temperature evolution during machining. We noted that at conventional cutting speed $\mathrm{Vc} \leq 250 \mathrm{~m} / \mathrm{min}$, normal cutting tool wear types (adhesion, abrasion and built up edge) are clearly observed. However, for cutting speed $\mathrm{Vc}>250 \mathrm{~m} / \mathrm{min}$ a severe wear is observed because the behavior of the WC-6Co grade completely changes due to a severe thermomechanical loading. Through all SEM micrographs, it is observed that this severe wear consists of several steps as: excessive deformation of WC-6Co bulk material and binder phase (Co), deformation and intragranular microcracking of WC, WC grain fragmentation and production of WC fragments in the tool/chip contact. Thus, the WC fragments accumulated at the tool/chip interface cause abrasion phenomena and pullout WC from tool surface. WC fragments contribute also to the microcutting and microploughing of chips, which lead to form a transferred layer at the tool rake face. Finally, based on the observations of the different wear micromechanisms, a scenario of WC-6Co damages is proposed through to a phenomenological model.
\end{abstract}

\author{
Keywords: \\ Turning \\ WC-6Co \\ Tool-chip contact \\ Microstructure \\ Wear mechanism \\ Temperature
}

\section{Introduction}

Machining is a largely used process for production of many parts in mechanical industry. Nowadays, the WC-Co cemented carbides are extensively used as cutting tools for their excellent wear resistance, high hardness and good chemical inertness. However, the manufacturing industries use cutting fluids in machining operations which are not environmentally friendly. On the one hand, to avoid the use of these cutting fluids, advanced dry machining is performed by manufacturing industries these last decades. On the other hand, in dry cutting, mainly for high cutting speeds, the cutting tool breaks down quickly and drastically. This is because high cutting speed leads to high heat generation

\footnotetext{
* Corresponding author at: Université de Lorraine, Laboratoire d'Énergétique et de Mécanique Théorique et Appliquée, LEMTA CNRS-UMR 7563, Ecole Nationale Supérieure des Mines de Nancy (ENSMN), GIP-InSIC, 27 rue d'Hellieule, 88100 Saint-Dié-desVosges, France. Fax: + 33329421825 .

E-mail address: tchadja.kagnaya@insic.fr (T. Kagnaya).

1 Now at: CERATIZIT Luxembourg S.a r.l. Route de Holzem L-8201 MAMER, Luxembourg.

${ }^{2}$ Now at: Institut PPrime UPR 3346, Département Thermique, Fluide et Combustion, Ecole Nationale Supérieure d'Ingénieurs de Poitiers (ENSIP), Bâtiment B25, Campus Sud, 2 rue Pierre Brousse, 86000 Poitiers, France.
}

and to severe tribological conditions on the tool surfaces, especially on tool rake face.

It is well known that cutting tool wear highly affects the parts' productivity, production costs and work piece surface integrity. So, a better understanding of the wear mechanisms during cutting remains essential.

Several studies dedicated to machining have been performed in order to understand the cutting tool wear [1-14]. Thus, it was generally found that: wear modes as abrasion, adhesion, plastic deconsolidation, oxidation, diffusion and chipping or notching are predominant under various cutting conditions. For example, Komvopoulos [3] reported that abrasive wear is observed on cutting tool when machining AISI 4340 . He pointed out that this is due to the combination of high temperature, high workpiece strength, work hardening and chip abrasion. This wear mode has been also reported by other authors [4-7]. Li and Liang [7] found that during turning at a cutting speed of $50 \mathrm{~m} / \mathrm{min}$, AISI 1045 steel adhered to the cutting edge. This adhesion is due to a combination of the ductile workpiece material behavior and of its thermal softening. These results are consistent with Kudou et al.'s [10] one. Furthermore, according to Kudou et al. [10], during high cutting speed machining of AISI 1045, a crater was formed on the tool rake face due to diffusion of cobalt from tool to the workpiece. Diffusion wear is mainly observed at the tool-chip 

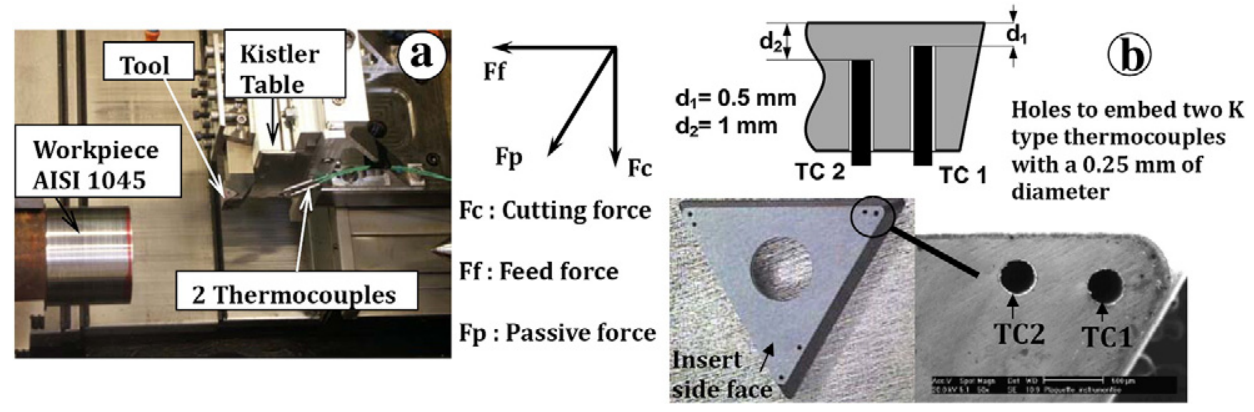

Fig. 1. (a) Experimental setup for machining tests, (b) detail of cutting tool insert.

interface and involves chemical reactions between workpiece and tool, because this process is thermally activated. This wear mode is more observed at high cutting speeds and essentially for dry machining. Devillez et al. [11] also observed a diffusion wear at rake face of WC-6Co cutting tool when machining AISI 4140 steel under high speed conditions.

This brief review of the cutting tools wear shows that the temperature is one of the most important parameters which influences the tool wear modes. Indeed, M'Saoubi and Chandrasekaran [12] characterized and identified the various friction zones and wear at the tool-chip interface, based on the temperature measurements by an infrared camera. Thus, lots of metal cutting processes are investigated [5,13-18] (numerically and experimentally) to determine the cutting tool temperature. These studies showed that the cutting tool temperature can often reach $1000{ }^{\circ} \mathrm{C}$, especially at tool-chip interface. Consequently, high temperature and severe friction phenomena at tool surfaces deeply modify the mechanical, chemical and thermo-physical properties and can change microstructure of WC-6Co [19-25]. For example Han et al. [19] show that for temperatures up to $1000{ }^{\circ} \mathrm{C}$, the WC-6Co has a strongly visco-plastic behavior and the accumulation of plastic deformation can reach $5 \%$. These observations were confirmed by Östberg et al. [20-22]. According to Childs [23], the oxidation phenomenon of WC-Co takes place at temperatures greater than $500{ }^{\circ} \mathrm{C}$. In addition, in the $900-950{ }^{\circ} \mathrm{C}$ temperature range, the mechanisms of dissolution of the tungsten carbide (WC) in the cobalt are activated and change the WC-Co microstructure. Although the mechanics of rock cutting differ to some extent from metal cutting, these observations were recently also confirmed by Beste et al. [24-26] and Angseryd [27] in rock drilling. Thus, Beste et al. [25] showed that the oxidation and the modification of the structure of Co lead to rapid WC-Co wear and a complex mixture of surface damage types, including fragmentation of WC grains.

It is clear that all these phenomena reduce dramatically the wear resistance of cutting tool material. Consequently, severe thermal, mechanical and thermo-mechanical solicitations on tool-workpiece and on toolchip interfaces lead to catastrophic tool wear. Thus, the study of the cutting tool wear still remains a challenge in machining processes, since the mechanisms of cutting tool wear in machining, are not yet clearly understood.

Thus the focus of this study is to identify and explain tool wear mechanisms in relation to the tool material properties and its microstructure. Observations and analyses at macro and micro scales are carried out to clarify complex and combined wear mechanisms of WC-6Co cutting tool. In addition, microanalyses are performed to determine the chemical composition on tool worn surfaces. Turning tests are carried out using AISI 1045 steel and an uncoated cemented carbide WC-6Co grade.

\section{Experiments setup}

\subsection{Machining experiments}

Cutting tests are carried out on a T400 REALMECA CNC turning machine with a spindle speed up to $4000 \mathrm{rpm}$ and a drive motor rated up to $7 \mathrm{~kW}$ (Fig. 1).

The workpiece material used throughout all these experiments is an AISI 1045 laminate steel in the form of round bars with $100 \mathrm{~mm}$ diameter. The mechanical properties, thermo-physical properties and chemical composition of workpiece are listed in Table 1. A pre-machining is made previously along the workpiece in order to eliminate any surface defect that could adversely affect the machining results.

A STCGL 2525M16 (40CrMoV12) tool holder with an uncoated insert TCMW $16 T 304$ (WC-6Co) is used. The cutting tool geometry characteristics, the chemical composition, and the physical and mechanical properties of this carbide tool grade are summarized respectively in Tables 2 and 3.

The test conditions are summarized in Table 4. For each experiment, a fresh part of the cutting tool is used and experiments are replicated twice for each cutting conditions in order to minor experimental error.

During experimental tests, two thermocouples ( $\mathrm{K}$ type) with $0.25 \mathrm{~mm}$ of diameter, are embedded in the cutting tool in order to measure the temperature evolution during machining process. The first (TC1) and the second (TC2) thermocouples are embedded respectively at $0.5 \mathrm{~mm}$ and $1 \mathrm{~mm}$ from the rake face of the cutting tool as shown in Fig. 1 (b). The three components of the cutting forces (cutting force Fc, feed force Ff, and depth of cut force Fp) are recorded for all the tests, using a dynamometer (KISTLER table, Model 9257B).

\subsection{Characterization methods}

Tool wear analyses are performed with two observation scales. Macroanalysis of tool wear is first performed with both optical microscopy (LOM) and quasi confocal optical scanning microscopy (COSM) Altisurf [28] to measure the geometrical parameters of the wear surface of the tool. The main advantage of the LOM, is to have a global view of
Table 1

Mechanical properties and chemical composition of AISI 1045 steel.

\begin{tabular}{llllllllll}
\hline Components & $\mathrm{C}$ & $\mathrm{Si}$ & $\mathrm{Mn}$ & $\mathrm{P}$ & $\mathrm{S}$ & $\mathrm{Cr}$ & $\mathrm{Ni}$ & $\mathrm{Mo}$ & $\mathrm{Cu}$ \\
\hline \%wt & 0.45 & 0.22 & 0.66 & 0.027 & 0.032 & 0.26 & 0.15 & 0.02 & 0.18 \\
Yield strength (MPa) & 437 & & & & & & & & \\
Rupture strength (MPa) & 704 & & & & & & & & \\
\hline
\end{tabular}

Table 2

Uncoated insert TCMW 16 T304 (WC-6\%Co) geometrical characteristics.

\begin{tabular}{ll}
\hline Nose radius & $0.4 \mathrm{~mm}$ \\
Cutting edge radius & $0.04 \mathrm{~mm}$ \\
Rake angle & $0^{\circ}$ \\
Clearance angle & $6^{\circ}$ \\
\hline
\end{tabular}


Table 3

Thermo-physical and mechanical properties of the cutting insert (WC-6Co)

\begin{tabular}{|c|c|c|c|c|c|c|c|}
\hline \multirow[t]{2}{*}{ Thermal conductivity } & Temperature $\left({ }^{\circ} \mathrm{C}\right)$ & 20 & 100 & 200 & 300 & 500 & 600 \\
\hline & Value $\left(\mathrm{W} / \mathrm{m}^{\circ} \mathrm{C}\right)$ & 117 & 110 & 97 & 86 & 85 & 83 \\
\hline Specific heat $\left(\mathrm{J} / \mathrm{kg}{ }^{\circ} \mathrm{C}\right)$ & 222 & & & & & & \\
\hline $\begin{array}{l}\text { Mean coefficient of thermal } \\
\text { expansion }\left(\mu \mathrm{m} / \mathrm{m}^{\circ} \mathrm{C}\right)\end{array}$ & 6.30 & & & & & & \\
\hline Density, $\rho\left(\mathrm{kg} / \mathrm{m}^{3}\right)$ & 14900 & & & & & & \\
\hline Young modulus (GPa) & 600 & & & & & & \\
\hline $\begin{array}{l}\text { Transverse rupture } \\
\text { strength (MPa) }\end{array}$ & 1620 & & & & & & \\
\hline Hardness $\mathrm{Hv}_{10}(\mathrm{MPa})$ & 1550 & & & & & & \\
\hline
\end{tabular}

the cutting tool wear surface, to identify the main wear modes and to measure some parameter of tool wear, as the flank wear width and the tool-chip contact length. However to obtain the crater wear depth and the crater wear volume, COSM Altisurf 820 apparatus with an optical probe having a precision of about $2 \mathrm{~nm} / \mathrm{mm}$ is carried out. The 3D rake face surface data processing is performed with the Altimap analysis software which offers a wide range of analysis and measures.

The observations of tool wear at the micro-scale are investigated with a scanning electron microscope (SEM) with back-scattered electron imaging (BSE). Energy dispersive spectroscopy (EDS) and X-ray mapping analysis with wavelength dispersive spectroscopy (WDS) are performed in order to identify the chemical elements at the surface of the cutting tool. All EDS spectra are performed using $20 \mathrm{kV}$ accelerating voltage and $\mathrm{X}$-ray mapping with WDS is complementary to EDS because it gives a better resolution for light elements as oxygen. All these analyses are useful for a better understanding of damage WC-6Co micromechanisms.

\section{Results and discussion}

\subsection{Cutting forces and temperature analysis}

Fig. 2 (a) presents the evolution of the cutting forces, generated during the AISI 1045 machining, versus the cutting speed. Fc, Ff and Fp are respectively the main cutting force, the feed force and the depth of cut force. The force component (Fig. 2) shows a decreasing trend with an increase in cutting speed, especially beyond $250 \mathrm{~m} / \mathrm{min}$. This evolution of cutting forces is in good agreement with general understanding in metal cutting [8]. One can notice that this reduction is particularly important with the feed force. Indeed, Fig. 2 (b) shows that the specific cutting energy, SCE, calculated by Eq. (1) varies slightly according to the cutting speed, while the tool-chip friction heat flux, Qf, obtained by Eq. (2) increases as cutting speed increases.

$\mathrm{S}_{\mathrm{EC}}=\frac{\mathrm{t}_{\mathrm{c}} \mathrm{VcFC}}{\mathrm{V}_{\mathrm{mat}}}$

$\mathrm{Q}_{\mathrm{f}}=\mathrm{V}_{\text {chip }}\left(\mathrm{F}_{\mathrm{f}}^{2}+\mathrm{F}_{\mathrm{p}}^{2}\right)^{1 / 2}$

where $V_{c}$ is the cutting speed $(\mathrm{m} / \mathrm{s}), \mathrm{V}_{\text {mat }}$ is the removed chip volume $\left(\mathrm{m}^{3}\right), \mathrm{t}_{\mathrm{c}}$ is the cutting time $(\mathrm{s})$, and $\mathrm{V}_{\text {chip }}$ is the chip flow velocity $(\mathrm{m} / \mathrm{s})$.

Table 4

Cutting test conditions.

\begin{tabular}{ll}
\hline Cutting speed & $100 \leq \mathrm{Vc}(\mathrm{m} / \mathrm{min}) \leq 500$ \\
Constant feed rate & $\mathrm{f}=0.1 \mathrm{~mm} / \mathrm{rev}$ \\
Constant depth of cut & doc $=1.1 \mathrm{~mm}$ \\
\hline
\end{tabular}
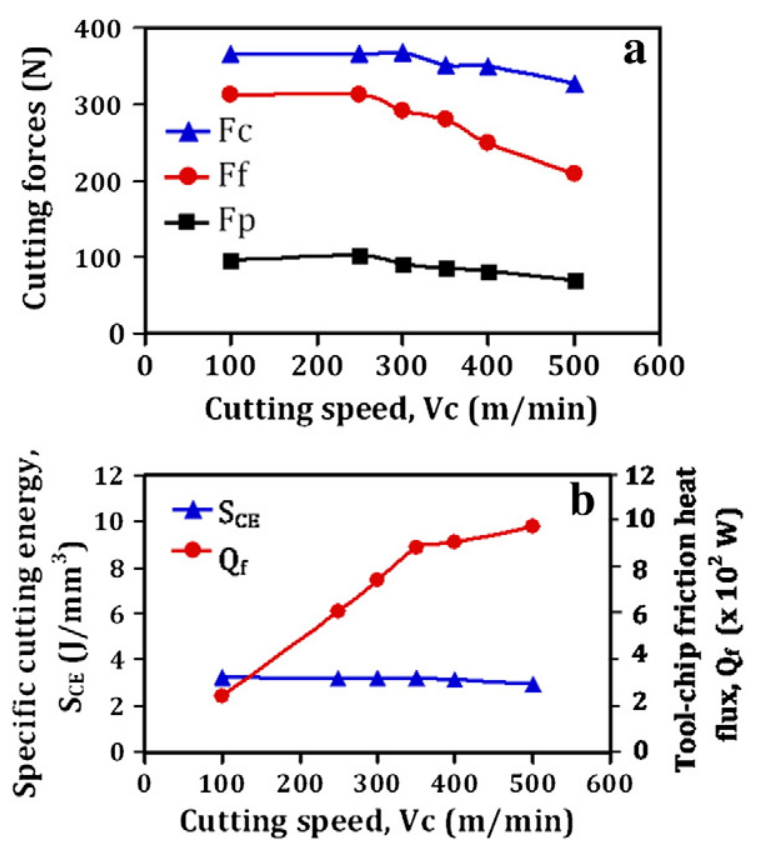

Fig. 2. (a) Cutting forces evolution, (b) specific cutting energy and tool-chip friction heat flux vs. cutting speed $(\mathrm{f}=0.1 \mathrm{~mm} / \mathrm{rev}$, doc $=1.1 \mathrm{~mm})$.

Therefore, the cutting force reduction can mainly be attributed to the softening of the AISI 1045. A higher cutting speed involves a higher heat flux and so a higher temperature (Figs. 2 (b) and 3). Thus, a high heat flux generated at high cutting speeds produces morphology changes of the chip and so, the outstanding feed force reduction is due to the chip segmentation [14].

To take into account the temperature in tool wear analysis, the cutting tool temperature is measured through two isolated K-type thermocouples $(\phi=0.25 \mathrm{~mm})$. Fig. 3 (a) and (b) shows the evolution of the cutting tool temperature (thermocouples TC1 and TC2), versus to cutting time and for four cutting speeds. Fig. 3 depicts that the temperature increases with increasing cutting speed and the reached temperature (about $600{ }^{\circ} \mathrm{C}$ ) is enough high to influence cutting tool wear.

For example, the highest temperatures recorded by the thermocouple nearest to the rake face (TC1), for the cutting speeds $100 \mathrm{~m} / \mathrm{min}$ and $400 \mathrm{~m} / \mathrm{min}$ after about $30 \mathrm{~s}$ of machining time, reach respectively of $400{ }^{\circ} \mathrm{C}$ and $820^{\circ} \mathrm{C}$. These temperatures are high enough to modify the tool material behavior and the microstructure of WC-6Co.

According to Fig. 3, it is observed that when the cutting speed " $\mathrm{Vc}$ " is lower than $300 \mathrm{~m} / \mathrm{min}$, the TC1 and TC2 temperatures become constant respectively $5 \mathrm{~s}$ and $10 \mathrm{~s}$ after the start of the experiment. On the other hand, for Vc $=400 \mathrm{~m} / \mathrm{min}$, TC1 and TC2 temperatures are not stabilized after $25 \mathrm{~s}$ of machining. Based on the TC1 and TC2 positions, the differences of the temperature evolutions between $\mathrm{Vc} \leq 300 \mathrm{~m} / \mathrm{min}$ and $\mathrm{Vc}=400 \mathrm{~m} / \mathrm{min}$ are due to the various heat input in the toolchip interaction areas (Fig. 2 (b)). This differences can also be due to the increase of the crater wear for $\mathrm{Vc}=400 \mathrm{~m} / \mathrm{min}$, i.e. a fast decrease of the distances between the thermocouples and the tool rake face and consequently the rapid increase of the recorded temperatures. These temperature measurements explain that two wear modes exist: a progressive wear mode for cutting speeds $\mathrm{Vc} \leq 300 \mathrm{~m} / \mathrm{min}$ and a fast wear mode for cutting speeds $\mathrm{Vc}>300 \mathrm{~m} / \mathrm{min}$. This conclusion is confirmed in Section 3.2.1 "Macroscopic scale tool wear analysis".

As mentioned above, temperature considerably impacts the cutting tool wear. However, direct temperature measurements at the toolchip and tool-workpiece interfaces are very difficult to get and even impossible because these interfaces are unattainable during machining 

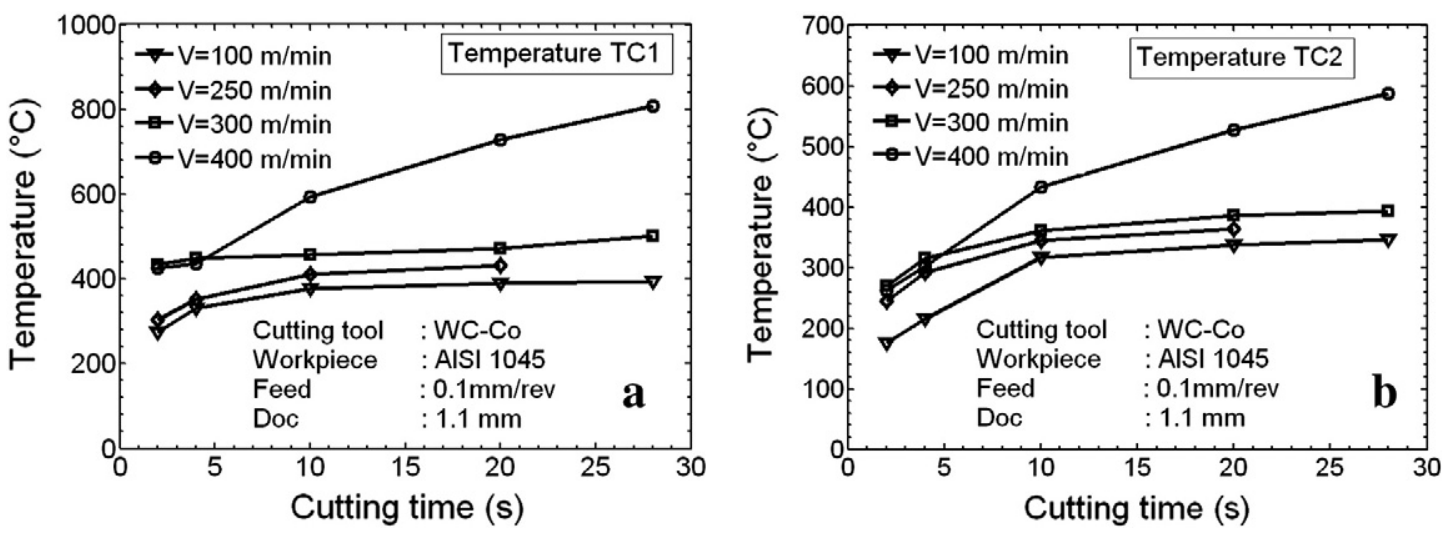

Fig. 3. Cutting tool temperature evolution vs. time for four cutting speeds: (a) - TC1; (b) - TC2.

process. So, the temperature distribution at tool-chip interface, obtained by numerical simulation and discussed in previous studies [14,29], is used to well analyze progressive tool-wear. Some results of these previous studies are presented here in order to better establish the correlation between temperature levels and WC-6Co damages.

Fig. 4 (a) presents the definition of the tool-chip contact area on which estimated values of friction heat flux, generated at chip-tool interface for each cutting condition, are applied to solve heat transfer numerical simulation. Fig. 4 (b) and (c) illustrates an example of the excessive temperature distribution with the high temperature gradient on tool- chip contact for the following cutting conditions: $\mathrm{Vc}=400 \mathrm{~m} / \mathrm{min}$, $\mathrm{f}=0.1 \mathrm{~mm} / \mathrm{rev}$ and doc $=1.1 \mathrm{~mm}$. For this example, the ultimate interface temperature varies between $1280{ }^{\circ} \mathrm{C}$ and $650{ }^{\circ} \mathrm{C}$. As it can be seen in Fig. 4 (b), two temperature profiles are plotted from the cutting tool edge to the end of tool-chip contact. The first profile corresponds to line 1 , which is located at $0.3 \mathrm{~mm}$ from the tool tip and the second one corresponds to line 2, which is located at $0.9 \mathrm{~mm}$ from the tool tip. According to Fig. 4 (c), the temperature along line 1 decreases from $1150{ }^{\circ} \mathrm{C}$ at the tool edge to $900{ }^{\circ} \mathrm{C}$, while the line 2 temperature decreases from $980{ }^{\circ} \mathrm{C}$ down to $760{ }^{\circ} \mathrm{C}$. Using these numerical simulation results, the average
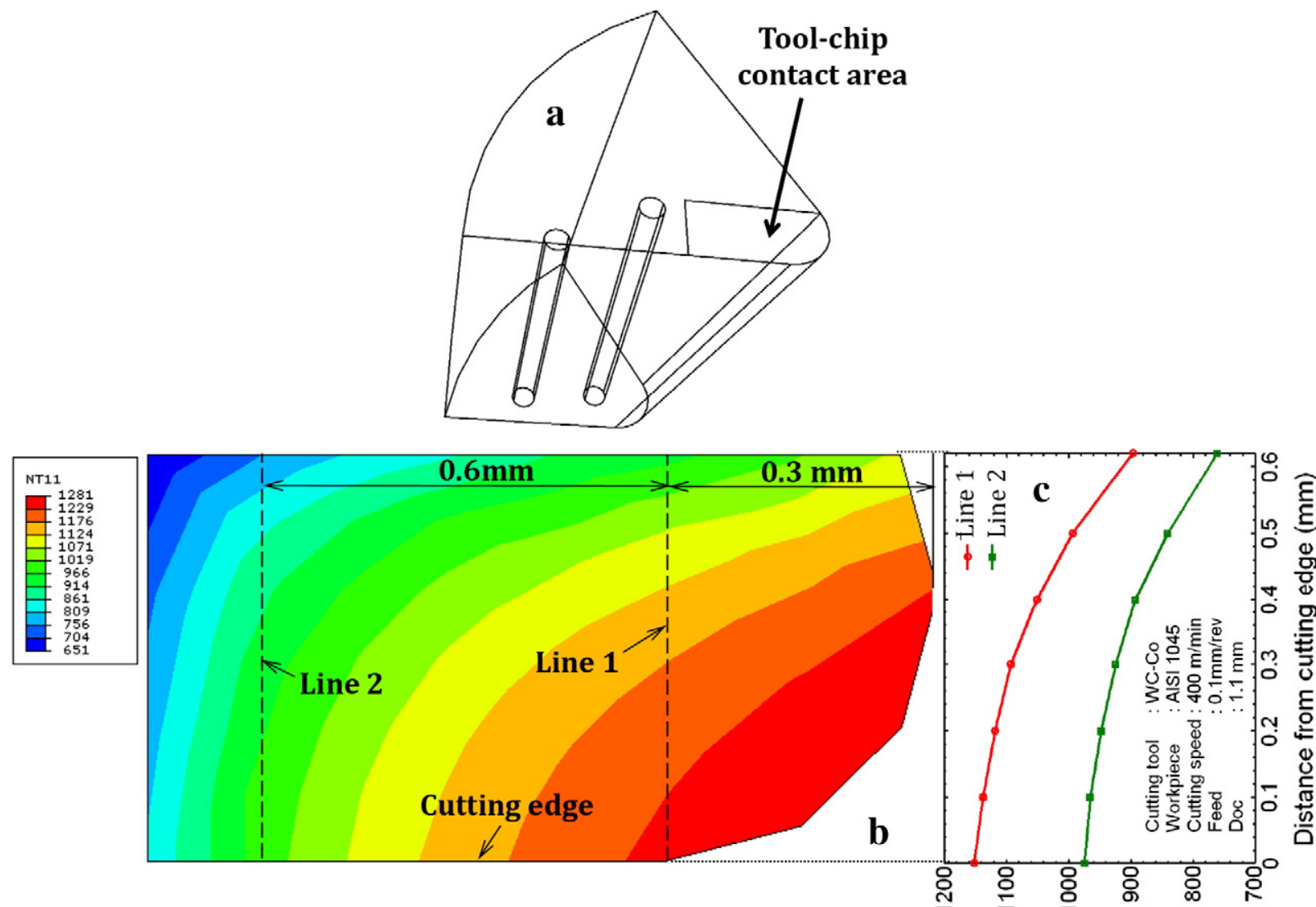

Tool-chip interface temperature $\left({ }^{\circ} \mathrm{C}\right)$

Fig. 4. Cutting tool: (a) definition of tool-chip contact area, (b) rake face temperature distribution, (c) temperature profiles on the rake face [14,24] $(\mathrm{Vc}=400 \mathrm{~m} / \mathrm{min}, \mathrm{f}=0.1 \mathrm{~mm} / \mathrm{rev}$, ap $=1.1 \mathrm{~mm}$, after end of cut). 


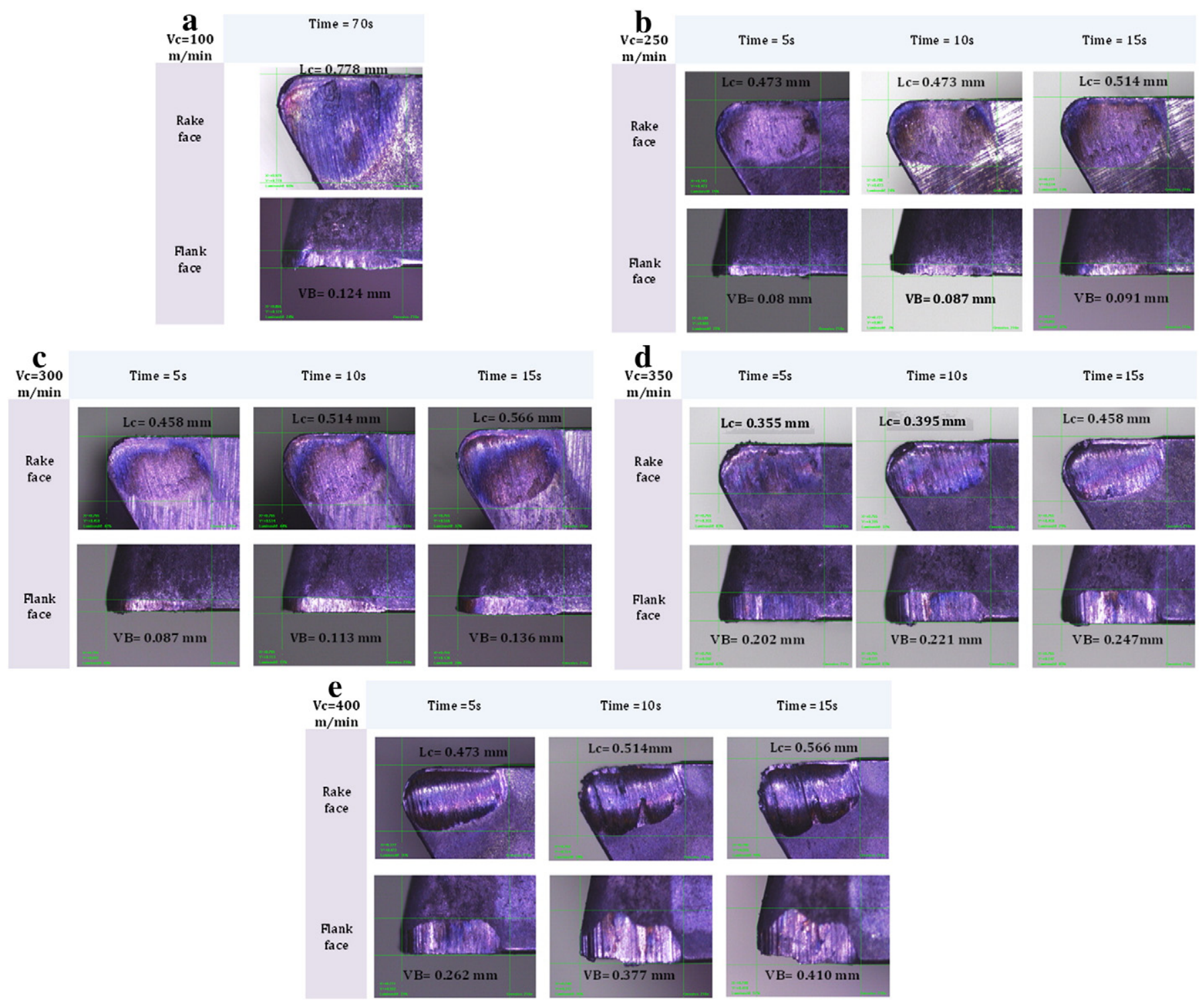

Fig. 5. Evolution of crater wear and flank wear of the cutting tools at macroscopic observations for different cutting speed, (magnification $216 \times$ ).

temperatures on tool rake face are calculated and are respectively $891^{\circ} \mathrm{C}$, $1002{ }^{\circ} \mathrm{C}$ and $1082{ }^{\circ} \mathrm{C}$ for cutting speeds of $250 \mathrm{~m} / \mathrm{min}, 300 \mathrm{~m} / \mathrm{min}$ and $400 \mathrm{~m} / \mathrm{min}$.

\subsection{Cutting tool wear analysis}

Fig. 5 illustrates progressive wear of the crater (rake face) and the flank face according various cutting times and cutting speeds (100250-300-350 and $400 \mathrm{~m} / \mathrm{min}$ ). These observations are in good agreement with time-temperature curve evolutions observed previously from Fig. 3. For each condition, tool-chip contact length, Lc (crater wear width) and flank wear width VB are measured. Lc and VB values increase according to cutting times for all cutting speeds. Fig. 5 also suggests that for the same time (for example time $=10 \mathrm{~s}$ ), increasing cutting speed induces an increase of VB. Instead, Lc is not a pertinent parameter since tool-chip contact length depends strongly on the competition between the chip curvature, the chip flow velocity and the local softening of the chip material.

At high speed machining, the wear of the tool rake face predominates and therefore tool life is determined by the crater wear depth until the edge failure occurs. For a good understanding of tool wear evolutions, mainly in terms of crater wear, a typical crater wear depth "KT" and crater wear volume "VKT" are measured with COSM. Fig. 6 (a) shows an example of 3D crater wear topography measured by COSM for $\mathrm{Vc}=500 \mathrm{~m} / \mathrm{min}$. Fig. 6 (b) illustrates the crater wear contour used to calculate the crater wear volume "VKT". Fig. 6 (c) illustrates one crater wear profile along the $\mathrm{x}$ axis which is perpendicular to the cutting edge according to Fig. 6 (a) and so, the values of crater wear depth "KT" in plane $(\mathrm{x}, \mathrm{z})$ can be measured. Fig. 7 shows the evolution of the KT and VKT values versus cutting speeds. For Vc $\leq 250 \mathrm{~m} / \mathrm{min}$, both KT and VKT are close to zero, however, above $\mathrm{Vc}=250 \mathrm{~m} / \mathrm{min}$, the increase of cutting speed induces the increase of both KT and VKT.

As previously mentioned, crater wear is more important at high cutting speed machining and only worn surfaces of the rake face were examined by integrating the temperature distribution at the tool-chip contact (Fig. 4). To extend our study, investigations from SEM micrographs are carried out. Therefore, macroscale and microscale tribological behaviors between tool and chip are studied from three wear zones as shows Fig. 8 (a) and (b) through SEM observations of the surfaces and cross-sections Fig. 8 (c). The analysis of WC-6Co cutting 

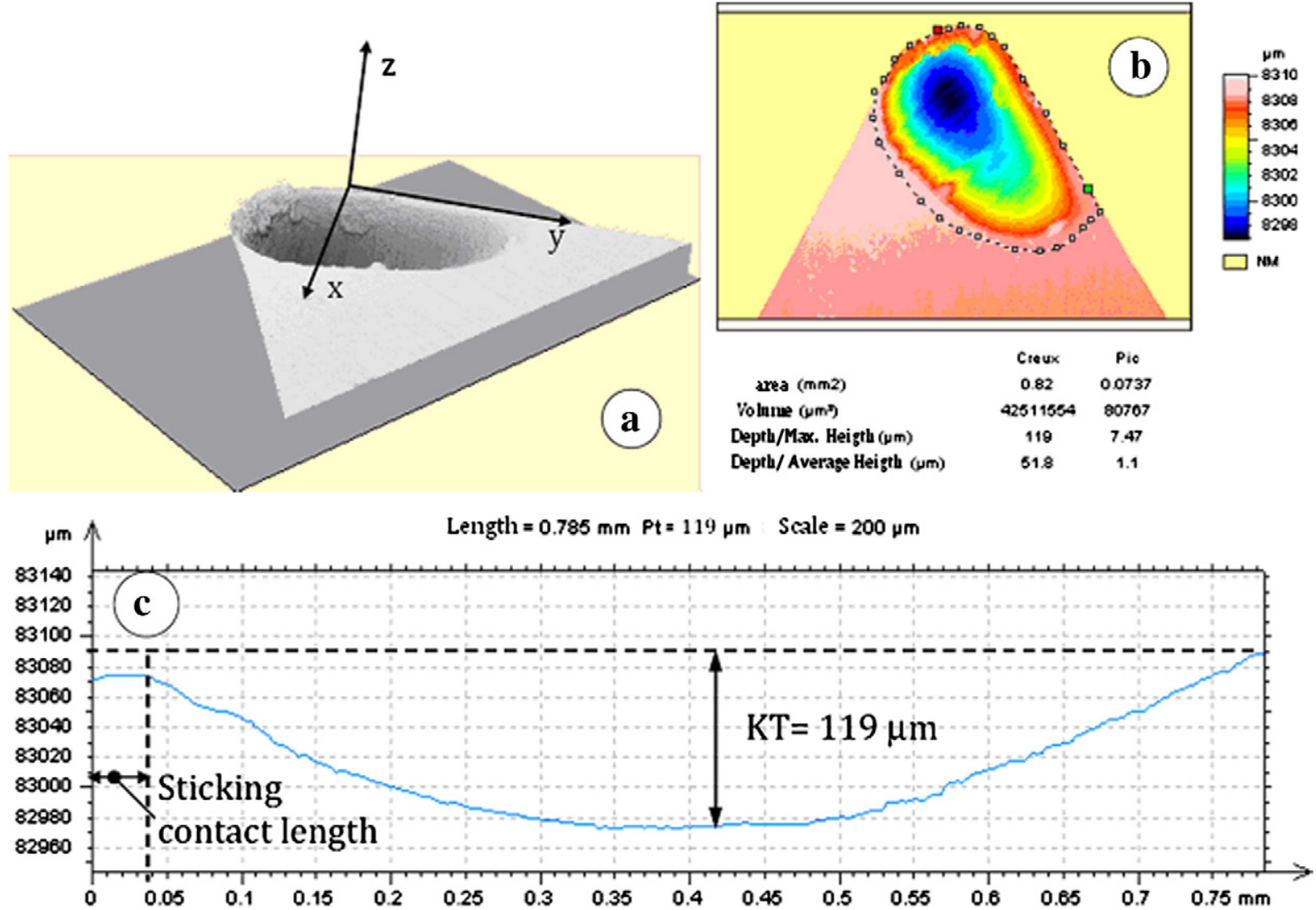

Fig. 6. (a) 3D crater wear topography ( $\mathrm{Vc}=500 \mathrm{~m} / \mathrm{min}$, feed $=0,1 \mathrm{~mm} / \mathrm{rev}$ et doc $=1,1 \mathrm{~mm}$ ), (b) determination of crater wear volume (VKT, $\mu \mathrm{m}^{3}$ ), (c) profile of crater perpendicular to cutting edge, determination of KT $(\mu \mathrm{m})$ in plane $(\mathrm{x}, \mathrm{z})$.

tool wear and discussion of each zone are presented separately including SEM observations and EDS analyses to evaluate adhesion of work material on worn surfaces of the cutting tool.

\subsubsection{Wear analysis in zone 1}

This small zone Fig. 8 (a), near to the cutting edge, corresponds to the sticking zone. In that zone, the contact surface appears smooth

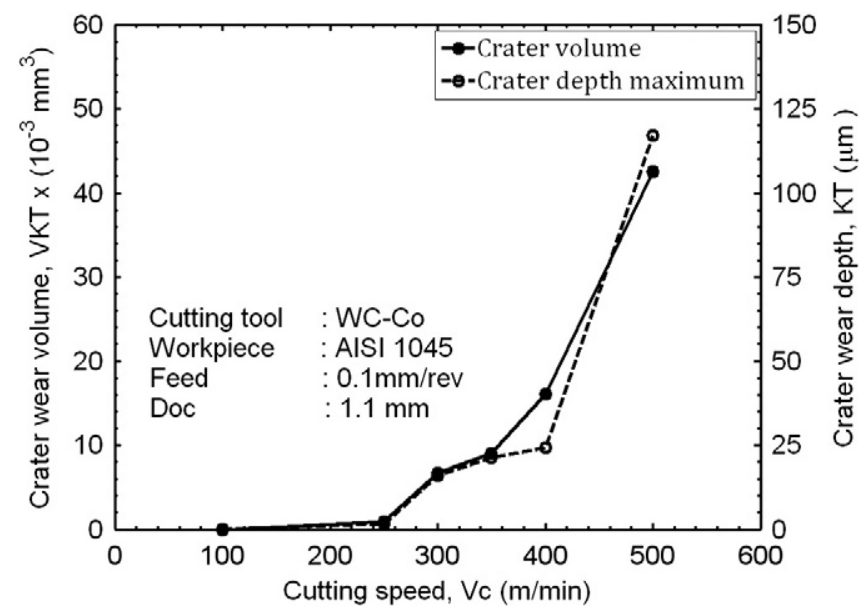

Fig. 7. Evolution of crater wear volume of and crater wear depth vs. cutting speed. and clean, which induces quasi-static friction, (sliding velocities are close to zero). This interpretation is confirmed by Zorev results [25] that identified this zone like an intimate contact tool-chip zone. The size of this zone is strongly affected by cutting speed and determines the position of the maximum crater wear depth, KT. The increase of the cutting speed leads to the decrease of the sticking zone. The size reduction of the sticking zone impairs the tool edge resistance. Then for high cutting speed, crater wear controls the cutting edge life. Higher normal and shear stresses (Fig. 8 (a)) in this zone are involved in the severe damage mechanisms.

Several damage modes are observed. The microstructure of WC-6Co appears disorganized (Fig. 9 (b), compared to the initial one Fig. 9 (a)). This disarrangement is the result of local intergranular microcracks at WC/WC or WC/Co interfaces or chipping due to the alternate stress and to the impact stress leading to particle release. One can note that microcracks extend at a distance equivalent to several grain sizes as shows Fig. 9 (c). In addition, plastic deformation steps of WC grains resulting from intragranular slips and probably according to crystallographic plans of WC, are observed on crater worm surface in Fig. 9 (d) (shown by slip lines on the surface of WC grains). Consequently, when the plastic deformation of WC is important, the intragranular microcracks could appear. But intragranular microcracks can also appear when a stress concentration exists at WC/WC. This wear mechanism was also observed by Beste et al. [25] in rock drilling. An example of intragranular microcrack is illustrated in Fig. 9 (e). The void observed in Fig. 9 (f) shows that the grains and/or the fragments of WC are time to time torn off from tool-chip contact. A small transferred layer is also observed in zone 1 and it represents WC-6Co/(chip material) weld junction. 

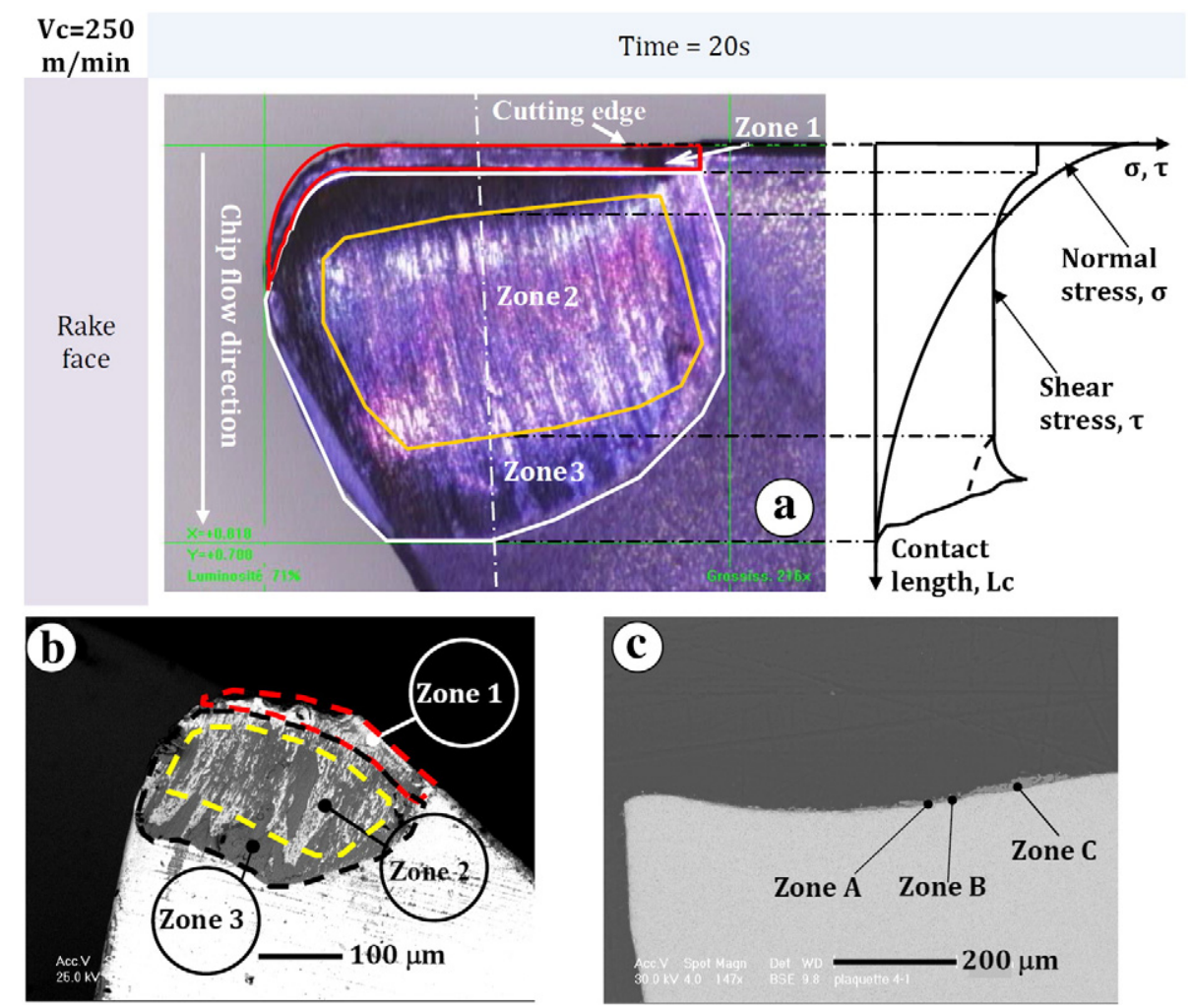

Fig. 8. (a) Evolution of normal and shear stress at tool-chip contact zones (feed $=0.1 \mathrm{~mm} / \mathrm{rev}$, doc $=1.1 \mathrm{~mm}$ ), (b) three zones define for wear analysis and (c) SEM micrographs of crater wear of the cutting tool cross-section, perpendicular to the cutting edge $(\mathrm{Vc}=400 \mathrm{~m} / \mathrm{min}$, feed $=0.1 \mathrm{~mm} / \mathrm{rev}$, doc $=1.1 \mathrm{~mm})$.

\subsubsection{Wear analysis in zone 2}

When the chip leaves the zone 1 , its velocity increases progressively up to a steady chip flow velocity. Therefore zone 2 corresponds to an intense tool-chip friction zone, in which the chip flow velocity is stable. The shear stress is optimum in this zone (Fig. 8 (a)). However due to the severe tribological conditions and to the high temperature levels at the tool-chip interface in this zone, the position of the maximum crater wear depth, KT is located in zone 2.

Damage micromechanisms observed in zone 2 are the same with those described for zone 1 except the process of disarrangement of the WC microstructure. However the phenomena of intergranular and intragranular microcracking as well as wrenching of WC grains are less important. The observation of Fig. 10 (a) shows several abrasive micro-scratches or slip line traces on the surface of WC grains in the chip flow direction. This second zone exhibits an important adhesion layer (Fig. 10 (b)) due to a combination of the high friction forces between the tool and the chip and the high temperature level in this zone. After its formation, adhesion layer could be periodically evacuated by the chip. This wear phenomenon can be summarized like following periodic phenomena of "formation-stacking (growth of adhesion layer)-pulling out". During adhesion layer elimination, more or less WC grains can be debonded and the presence of the WC grain in adhesion layer (Fig. 10 (b)) illustrates this remark. These wear debris, i.e. WC grain fragments, could increase the abrasion phenomena on rake face, during the machining process.

\subsubsection{Wear analysis in zone 3}

It is a crown shape zone, which is surrounded by zone 2 (Fig. 8 (a)). It characterizes the entry and the exit of the intense friction zone (artificial secondary rake face and artificial backwall contact zones). In this zone, adhesion of the machined material is more important. When the chip leaves the zone 1 , the shear stress starts to decrease and reach an optimum. Towards the exit of the chip, under the effect of the contact pressure and chip curvature, an unsticking resistance of the chip appears which involves an increase in the shear stresses before these stresses relapse to zero when the chip loses its contact with the tool.

In zone 3, an important adhesion layer is formed as shown in Fig. 11. The curvature and intense shear deformation of the chip in this zone induce chip ploughing phenomenon and so, can explain this important adhesive layer. The accumulation of workpiece material in this zone modified strongly the parameters of the cutting rake face geometry (rake angle for example).

\subsubsection{Complementary EDS and X-ray mapping analysis}

According to some studies [10,30-32], diffusion wear mechanism can occur at tool-chip interface when machining free cutting steels because $\mathrm{Co}$ and $\mathrm{W}$ elements can move towards chip material and $\mathrm{Fe}$ element can diffuse into WC-6Co material.

In order to investigate the effect of diffusion wear mechanism on the crater wear process, EDS analysis is performed in small zone (ZA) as it can be seen in the cross-section of Fig. 11 (c) and the result of the EDS analysis is shown in Fig. 12. Except for oxygen element, all the chemical components detected in the adhesion layer are the same ones as those of the workpiece material. The high oxygen content indicates that the adhesion layer is oxidized, as a consequence of the elevated temperature generated at tool-chip according to Fig. 4 (b). EDS results indicated that $\mathrm{Co}$ and $\mathrm{W}$ elements have not diffused into the adhesion layer.

In certain circumstances, EDS results may contain peak overlaps for iron and cobalt components. So 2D element maps with WDS which can detect trace elements are very useful for displaying element distributions in sample. Fig. 13 shows the spatial distribution of four elements (Fe in Fig. 13 (a), $\mathrm{O}$ in Fig. 13 (b), W in Fig. 13 (c) and Co in Fig. 13 (d)) according in square zone defined by dotted lines on Fig. 11 (c). From qualitative point of view, the high concentration of white pixels in the images indicates a high content of the considered element. The position of (adhesion layer)/(WC-6Co) interface is materialized by a dotted lines. In the adhesion layer, the higher content of Fe compared to $\mathrm{O}, \mathrm{W}$ or Co can be observed, and the presence of oxygen confirms that the 


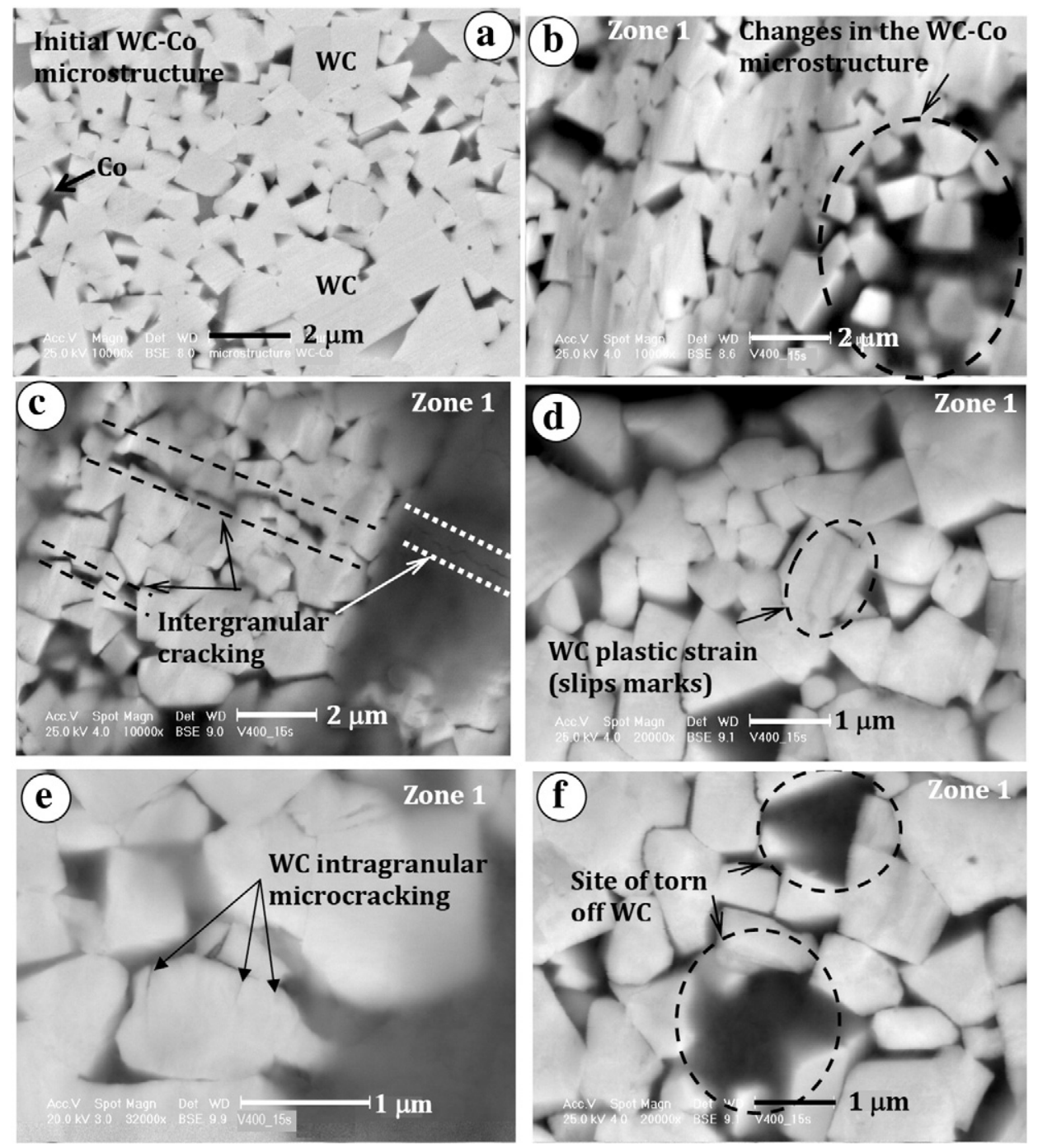

Fig. 9. (a) Initial micrograph of WC-6Co, (b)-(f) crater wear SEM micrographs for detail observations zone 1in Fig. 8b.
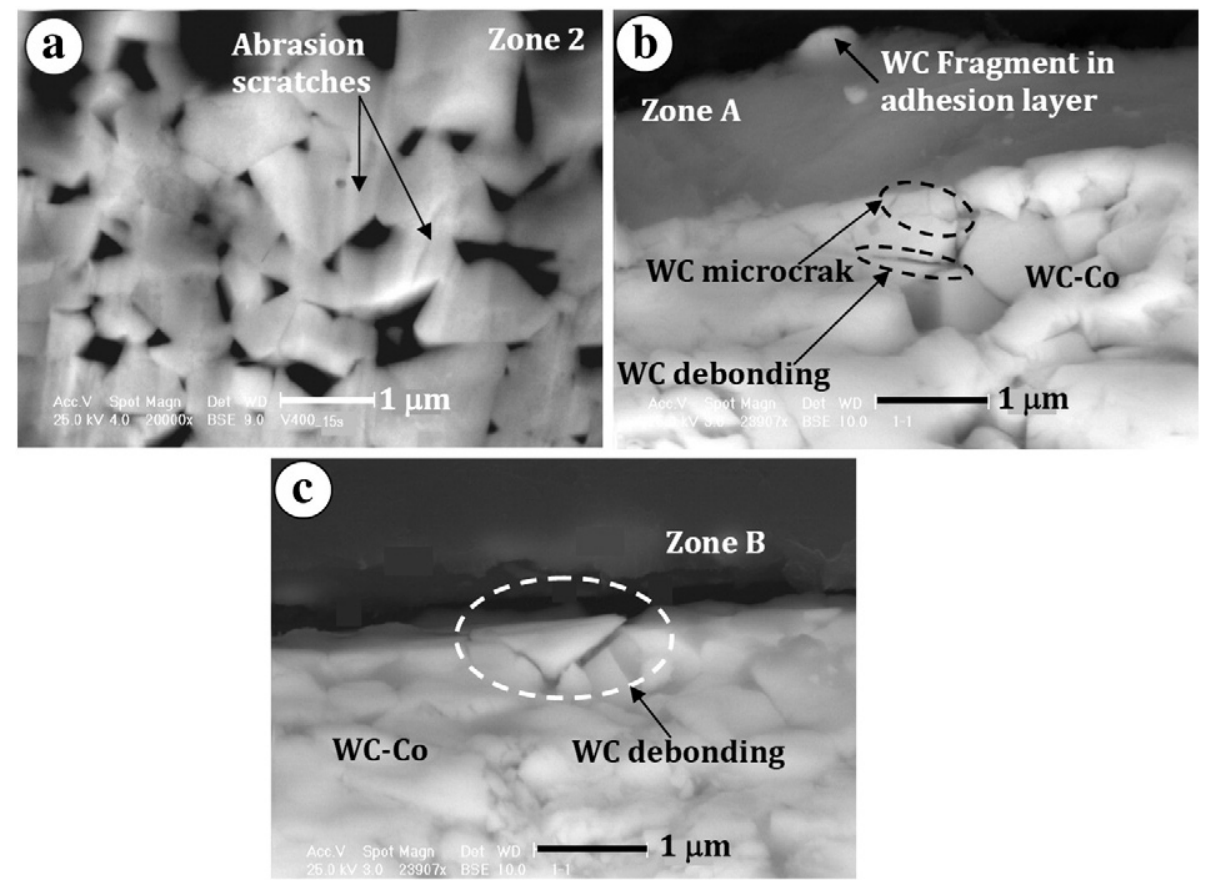

Fig. 10. Crater wear SEM micrographs for detail observations: (a) zone 2 in Fig. 8b, (b) zone A and (c) zone B in Fig. 8c. 


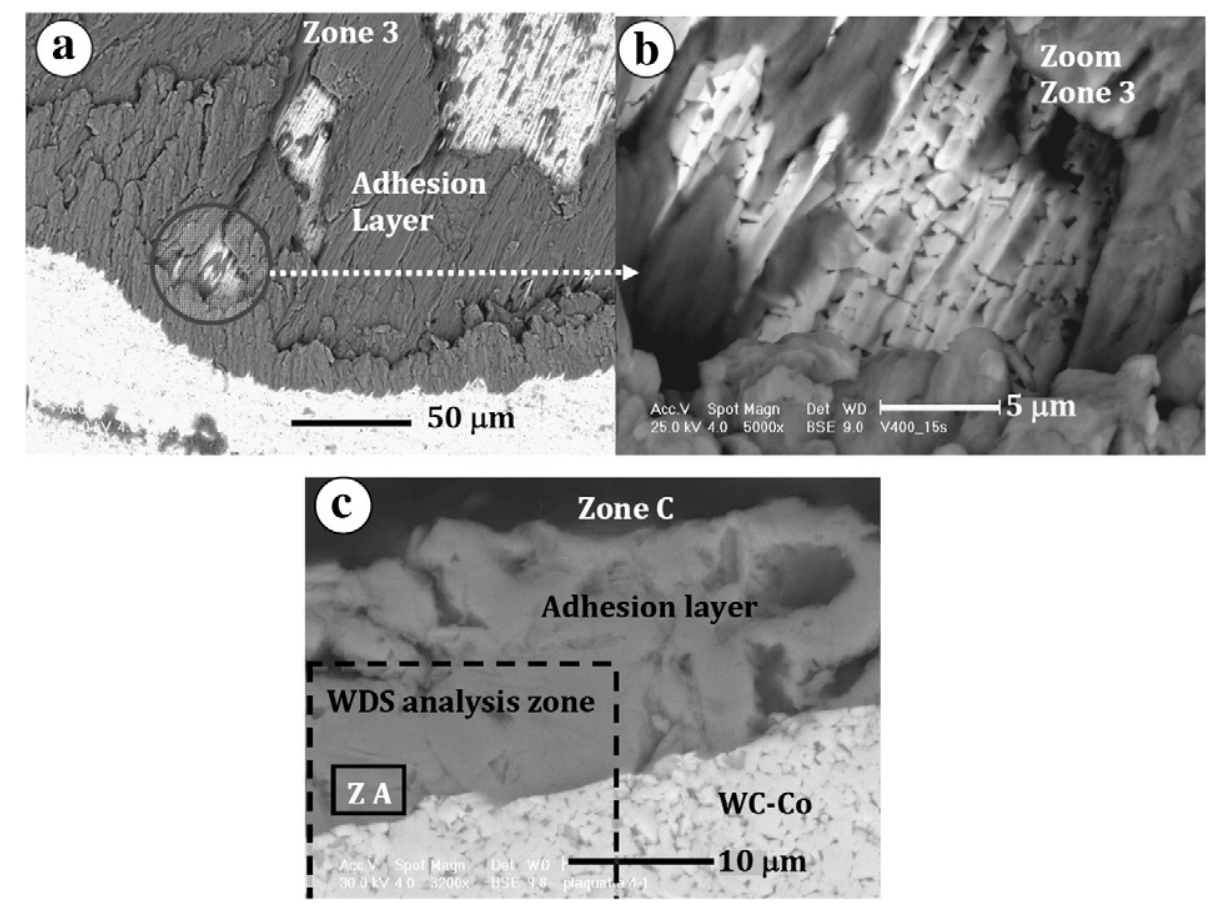

Fig. 11. Crater wear SEM micrographs for detail observations: (a) and (b) zone 3 in Fig. 8b, (c) zone C in Fig. 8c.

adhesion layer is oxidized. As observed in element maps shown in Fig. 13 (c), bottom part of dotted line zone contains a large amount of tungsten and the concentration of Co can be considered as insignificant compared to W (Fig. 13 (d)).

Through chemical analyses, it is not obvious to conclude that there is diffusion of the tool elements into the adhesion layer (the chip) and vice-versa. However, the diffusion wear phenomena takes perhaps place in the thin adhesion layer at tool-chip interface and consequently requires other more powerful techniques than those carried out in this study.

A qualitative summary of the WC-6Co damage mechanisms, which were identified through SEM, EDS and WDS analyses is presented in Table 5. Therefore Section 3.2.5 presents complementary phenomenological models suggested to detail the micromechanisms that control the wear behavior mentioned above.

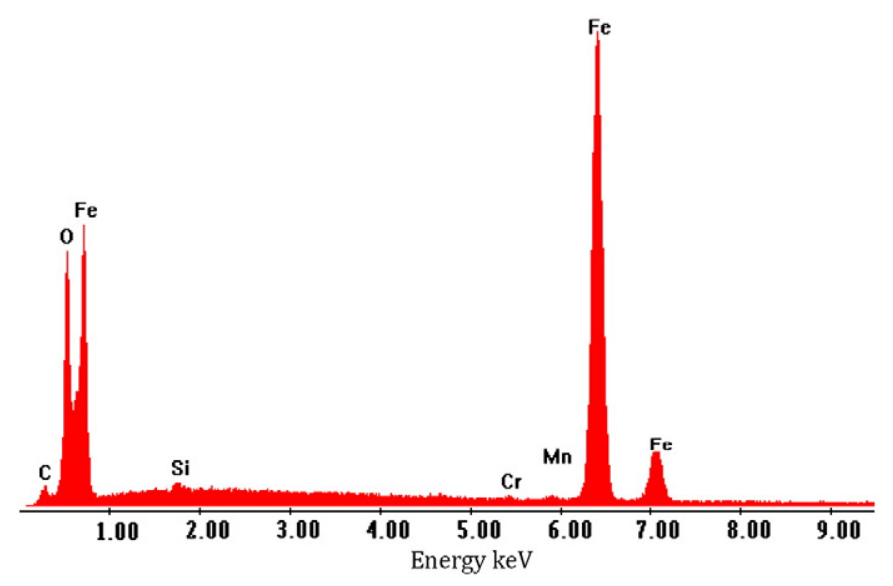

Fig. 12. EDS analysis on the adhesion layer in cross-section (small square zone ZA Fig. 11c).

\subsubsection{Discussion of the phenomenological model}

It is important to note that during the machining process, numerous complex and intensive interactions occur in the cutting zone, mainly at the tool-chip interface. These interactions result in different phenomena like friction, plastic and elastic deformations, chemical reactions and heat generation. These solicitations become more severe in dry high speed machining and lead to a faster tool wear. On the basis of observations carried out in this present work, the aim of this section is to propose model to explain the damage mechanisms of the WC-6Co. Fig. 14 presents this phenomenological model that has been established from the tool wear mechanisms identified mainly in zone 2 of crater wear.

3.2.5.1. Stage 1. Under severe friction conditions (high shear stresses) at the tool-chip interface, the local temperature rises up to several hundreds of degrees (about $1280{ }^{\circ} \mathrm{C}$-Fig. 4 (b)). Referring to the results of Östberg et al. [20], such a temperature level can lead to the plastic deformation of WC-6Co, because plastic deformation transition of the WC-6Co appears towards $900{ }^{\circ} \mathrm{C}$. Moreover at such temperature level, the binder phase, which is a Co-W-C alloy, becomes very ductile since its melting point is lower than that of pure cobalt $\left(1500{ }^{\circ} \mathrm{C}\right)$. Thus, the binder phase between the WC grains can be extruded or partially removed, due to the movement of the WC grains at the crater surface. These phenomena involve a rearrangement between the WC grains and the binder phase as that is observed in Fig. 9 (b) and can start the debonding mechanism of the WC grains as schematized by Fig. 14 (a).

3.2.5.2. Stage 2. Locally, when the binder phase between the $\mathrm{WC}$ grains is removed, and hard-on-hard WC/WC contacts are established, an increase of the stress level in the WC grains occurs. Taking into account the angular shape of the WC grains, stress concentrations appear at angular contact points as shown in Fig. 14 (b).

3.2.5.3. Stage 3. Due to stress concentrations, temperature and cyclic mechanical loadings during machining, the intragranular deformation mechanisms of WC grains are activated as observed in Fig. 8 (c) and as shown schematically in Fig. 14 (c). The plastic deformations observed 


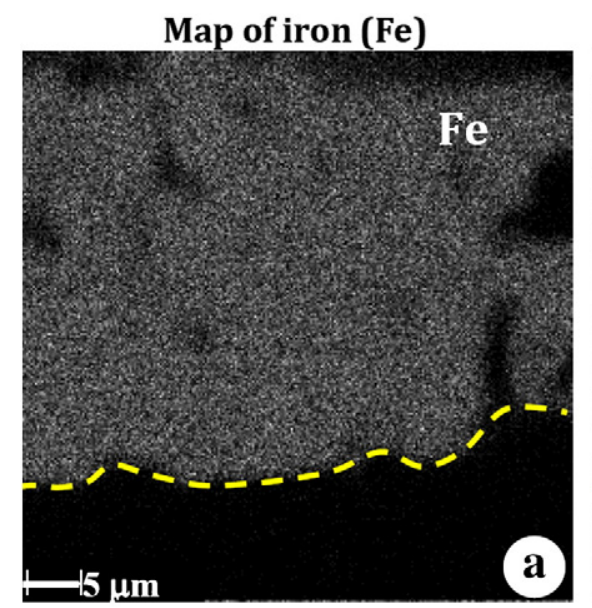

Map of tungsten (W)

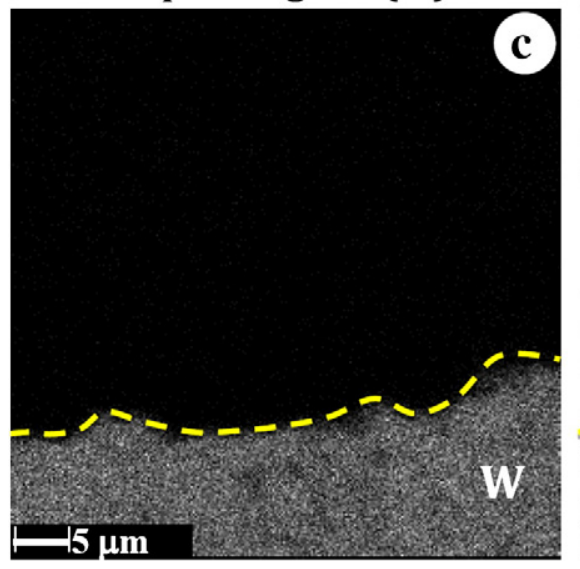

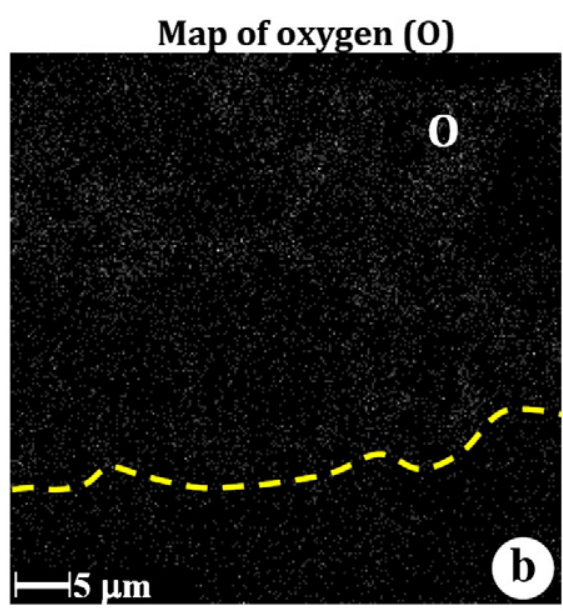

Map of cobalt (Co)

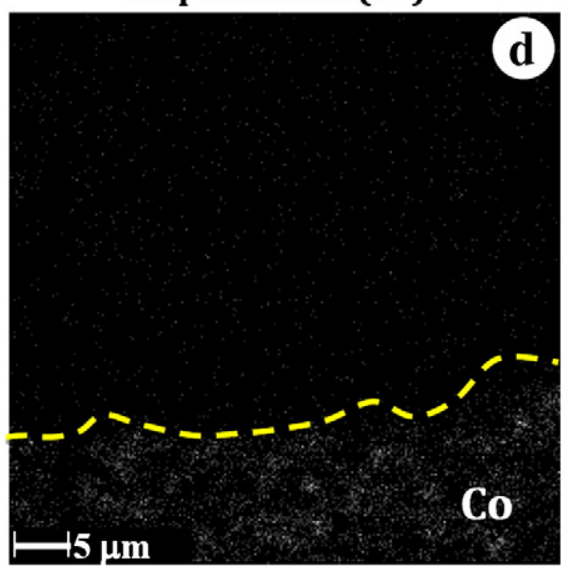

Fig. 13. X-ray analysis and elemental mapping obtained by WDS analysis (see Fig. 11c): (a) Fe map; (b) O map; (c) W map; (d) Co map.

in WC grains are in good agreement with the results of literature $[19,20,33]$. Furthermore, such intragranular phenomena can initiate microcracks. Furthermore, the decrease of WC hardness above of $800{ }^{\circ} \mathrm{C}$ [34], can lead to intragranular propagation of the microcrack after its initiation. This mechanism produces fragments of WC grains as observed previously in the underlying layer at the friction surface in Fig. 10 (b).

3.2.5.4. Stage 4. When the WC fragments are produced, they are embedded in chip or in the adhesion layer and they take part both in abrasive wear mechanism at tool rake face and in the debonding process of the WC grain, as shown in Fig. 14 (e)-(f). Moreover, towards the toolchip separation zone, especially strong adhesion layer is formed. It is due to the fact that in this zone both mechanical loads (normal pressure and shear stress) and the temperature levels are less important compared to those of zones 1 and 2 .

\section{Conclusions}

This work provides a better understanding of the different damage at the micro-scale of WC-6Co in machining processes. The main conclusions of the present work can be summarized as follows:

- The cutting tool temperature increases with the cutting speed, while cutting forces decrease as cutting speeds increase. Increasing the cutting tool temperature leads to decrease the friction coefficient and consequently the cutting pressure.

- The cutting tool wear depends on cutting speed. At conventional cutting speeds, a normal wear of the flank tool is observed. For high cutting speeds, a faster wear rate on the rake face is predominant. At a macroscopic scale, adhesion, abrasion and chipping wear are observed. The crater wear mode is dominant during machining AISI 1045 at high cutting speeds with WC-6Co cemented carbide cutting tools.

- The catastrophic wear mechanism of WC-6Co tools during highspeed machining of AISI 1045 is activated by the coexistence of two main factors: severe tribological conditions on cutting tool and heat generation. These conditions lead to the following tool wear micromechanisms:

- Disarrangement of the WC-6Co macrostructure due to the severe tribological conditions at tool-chip and tool-workpiece interfaces. This disarrangement leads to microcracks at WC/WC or at WC/Co interfaces or chipping due to the alternative stress and to the impact stress.

- Plastic deformation and intragranular microcraking of the WC grains. This intragranular microcraking leads to the fragmentation of WC grains and to the production of WC debris at the tool-chip interface. - According to SEM observations, there is adhesion at the tool-chip separation zone and this adhesive layer is formed according to a "formation-stacking-pulling out" process. During machining, it is removed periodically by the chip and this removal can be amplified by the debonding of WC fragments.

- From the chemical analyses carried out in the zone of strong adhesion, it is not obvious to conclude that there is diffusion of the tool elements in the adhesion layer (the chip) and vice-versa. However, the diffusion wear phenomenon perhaps takes place in the thin adhesion layer at tool-chip interface and consequently requires other techniques than those used in our investigations. 
Table 5

WC-6Co identified damage mechanisms through the SEM, EDS and WDS analyses.

\begin{tabular}{llll}
\hline & Zone 1 & Zone 2 & Zone 3 \\
\hline $\begin{array}{l}\text { WC-6Co microstructure changing } \\
\quad \text { and disorganization }\end{array}$ & $\mathrm{X}$ & & \\
$\begin{array}{l}\text { Intergranular microcracking } \\
\text { Intergranular slip system }\end{array}$ & $\mathrm{X}$ & & \\
Intragranular microcracking & $\mathrm{X}$ & $\mathrm{X}$ & \\
Void due to WC fragments torn off & $\mathrm{X}$ & $\mathrm{X}$ & \\
WC abrasive micro-scratches & & $\mathrm{X}$ & \\
Built-up layer & $\mathrm{X}$ & $\mathrm{X}$ & \\
Diffusion wear & Possible & Possible & Possible \\
\hline
\end{tabular}

- Finally, a phenomenological model is proposed in order to identify the different wear sequences of the WC-6Co tool during dry turning process.

\section{Acknowledgments}

Authors thank ACTARUS S.A.S. Company and European Research Center for Rapid Prototyping and Rapid Tooling (CIRTES) for supporting this work.

\section{References}

[1] Lim CYH, Lau PPT, Lim SC. The effects of work material on tool wear. Wear 2001:250:344-8.

[2] Liu Q Altintas Y. On-line monitoring of flank wear in turning with multilayered feed-forward neural network. Int J Mach Tool Manuf 1999;39:1945-59.

[3] Cho SS, Komvopoulos K. Wear mechanisms of multi-layer coated cemented carbide cutting tools. J Tribol-T ASME 1997;119:8-17.

[4] Liao YS, Shiue RH. Carbide tool wear mechanism in turning of Inconel 718 superalloy. Wear 1996;193:16-24

[5] List G, Nouari M, Géhin D, Gomez S, Manaud JP, Le Petitcorps Y, et al. Wear behaviour of cemented carbide tools in dry machining of aluminium alloy. Wear 2005;259:1177-89.

[6] Nouari M, Iordanoff I. Effect of the third-body particles on the tool-chip contact and tool-wear behaviour during dry cutting of aeronautical titanium alloys. Tribol Int 2007;40:1351-9.

[7] Li KM, Liang SY. Modeling of cutting forces in near dry machining under tool wear effect. Int J Mach Tool Manuf 2007:47:1292-301.

[8] Ebrahimi A, Moshksar MM. Evaluation of machinability in turning of microalloyed and quenched-tempered steels: tool wear, statistical analysis, chip morphology. J Mater Process Technol 2009;209:910-21.

[9] Venugopal KA, Paul S, Chattopadhyay AB. Tool wear in cryogenic turning of Ti-6Al4v alloy. Cryogenics 2007;47:12-8.

[10] Kudou K, Ono T, Okada S. Crater wear characteristics of an Fe-diffused carbide cutting tool. J Mater Process Technol 2003;132:255-61.

[11] Devillez A, Lesko S, Mozer W. Cutting tool crater wear measurement with white light interferometry. Wear 2004;256:56-65.

[12] M'Saoubi R, Chandrasekaran H. Innovative methods for the investigation of toolchip adhesion and layer formation during machining. Cirp Ann-Manuf Techn 2005;54:59-62.
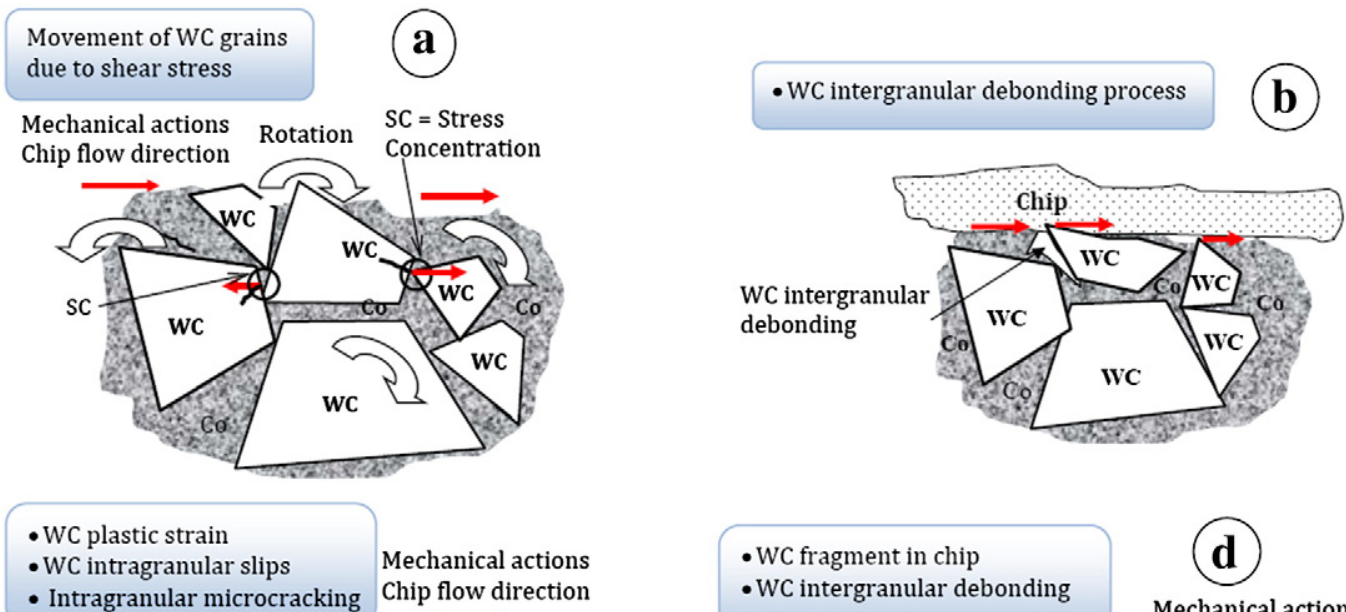

- Intragranular microcracking Chip flow direction

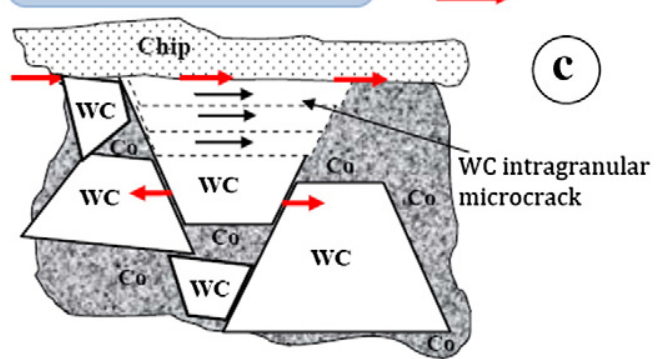

-WC intergranular debonding process
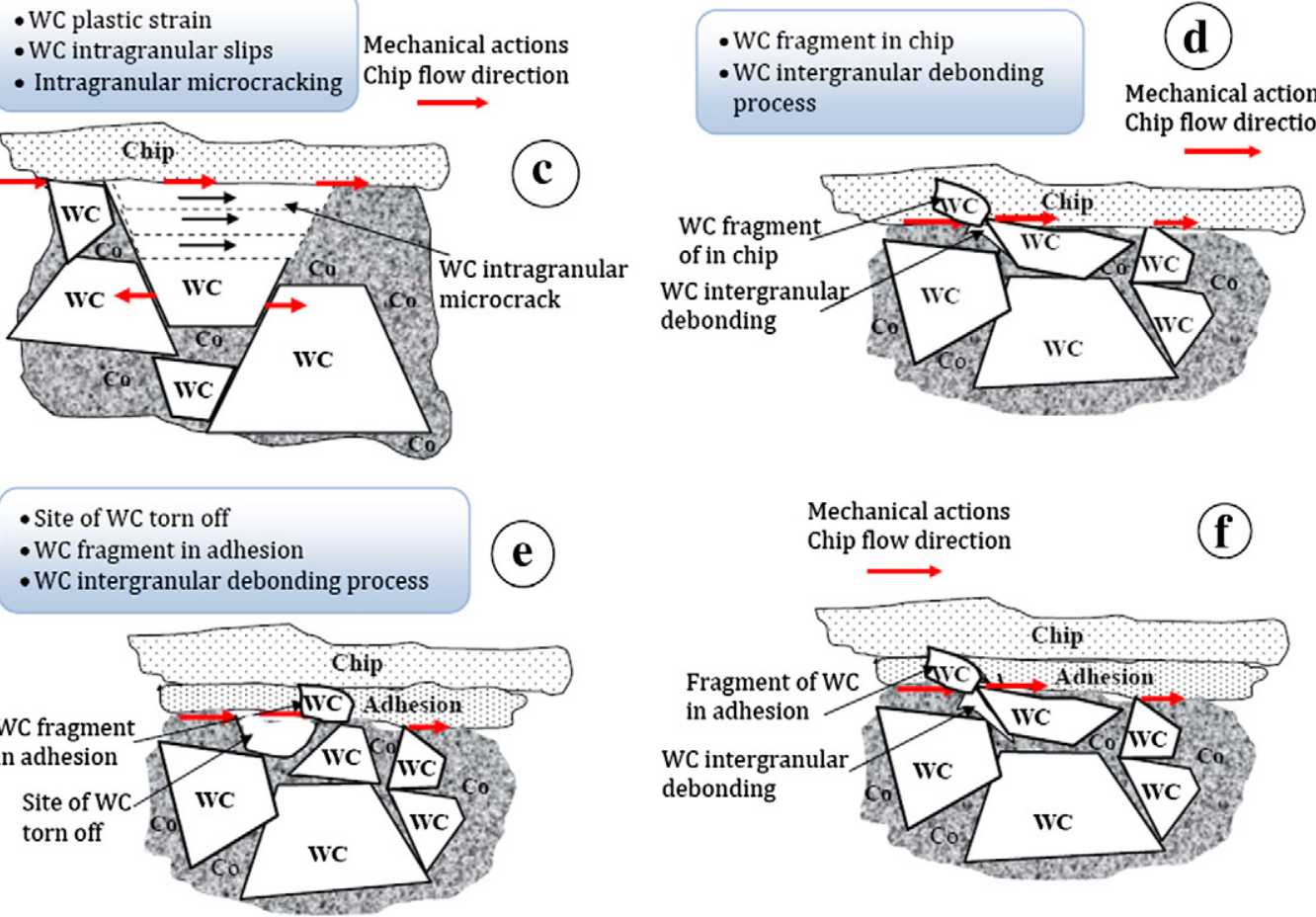

Fig. 14. Wear micromechanisms phenomena identified in crater. 
[13] Choudhury SK, Bartarya G. Role of temperature and surface finish in predicting tool wear using neural network and design of experiments. Int J Mach Tool Manu 2003;43:747-53.

[14] Kagnaya T. Contribution à l'identification des mécanismes d'usure d'un WC-6\%Co en usinage et par une approche tribologique et thermique. [ $\mathrm{PhD}$ thesis] École des Mines de ParisTech; 2009.

[15] Arsecularatne JA. On prediction of tool life and tool deformation conditions in machining with restricted contact tools. Int J Mach Tool Manuf 2003;43:657-69.

[16] Fang XD. Experimental investigation of overall machining performance with overall progressive tool-wear at different tool faces. Wear 1994:173:171-8.

[17] Abdel-Aal HA, Nouari M, El Mansori M. Tribo-energetic correlation of tool thermal properties to wear of WC-6Co inserts in high speed dry machining of aeronautical grade titanium alloys. Wear 2009;266:432-43.

[18] Kitagawa T, Kubo A, Maekawa K. Temperature and wear of cutting tools in highspeed machining of Inconel 718 and Ti-6Al-6 V-2Sn. Wear 1997:202:142-8.

[19] Han X, Sacks N, Milman YV, Luyckx S. On plastic deformation mechanisms of WC $15 \mathrm{wt} \%$ Co alloys at $1000{ }^{\circ} \mathrm{C}$. Int J Refract Met Hard Mater 2009;27:274-81.

[20] Östberg G, Buss K, Christensen M, Norgren S, Andrén HO, Mari D, et al. Mechanisms of plastic deformation of WC-Co and $\mathrm{Ti}(\mathrm{C}, \mathrm{N})-\mathrm{WC}-\mathrm{Co}$. Int J Refract Met Hard Mater 2006;24:135-44.

[21] Östberg G, Buss K, Christensen M, Norgren S, Andrén HO, Mari D, et al. Effect of TaC on plastic deformation of WC-Co and Ti(C, N)-WC-Co. Int J Refract Met Hard Mater 2006;24:145-54.

[22] Östberg G, Farooq MU, Christensen M, Andrén HO, Klement U, Wahnström G. Effect of $\sum 2$ grain boundaries on plastic deformation of WC-Co cemented carbides. Mater Sci Eng A-Struct 2006;416:119-25.
[23] Childs T, Maekawa K, Obikawa T, Yamane Y. Metal machining: theory and applications. John Wiley \& Sons Inc.; 2000

[24] Beste U, Coronel E, Jacobson S. Wear induced material modification of cemented carbide rock drills. Int J Refract Met Hard Mater 2006;24:168-76.

[25] Beste U, Jacobson S. A new view of the deterioration and wear of WC/Co cemented carbide rock drill buttons. Wear 2008;264:1129-41.

[26] Beste U, Jacobson S, Hogmark S. Rock penetration into cemented carbide drill buttons during rock drilling. Wear 2008;264:1142-51.

[27] Angseryd J, Johan Wallin A, Jacobson S, Norgren S. On a wear test for rock drill inserts. Wear 2013;301:109-15.

[28] http://www.altimet.fr.

[29] Kagnaya T, Lazard M, Boher C, Lambert L, Cutard T. Temperature evolution in a WC-6\%Co cutting tool during turning machining: experiment and finite element simulations. Heat Mass Transf-T WSEAS1790-5044 2011;6: 71-80.

[30] Zorev NN. Inter-relationship between shear processes occurring along tool face and shear plane in metal cutting. International Research in Production Engineering ASME, New York; 1963. p. 42-9.

[31] Giménez S, Huang SG, Vander Biest O, Vleugels J. Chemical reactivity of PVD-coated WC-Co tools with steel. Appl Surf Sci 2007;253:3547-56.

[32] Ramanujachar K, Subramanian SV. Micromechanisms of tool wear in machining free cutting steels. Wear 1996;197:45-55.

[33] Mari D, Krawitz AD, Richardson JW, Benoit W. Residual stress in WC-Co measured by neutron diffraction. Mater Sci Eng A-Struct 1996;209:197-205.

[34] Sakuma T, Hondo H. Plastic flow in WC-13 wt\% Co at high temperatures. Mater Sci Eng A-Struct 1992;156:125-30. 